\title{
Application Appraisal of Government Micro-blogging on Citizens: An Empirical Study of Western China
}

\author{
Zezhao Liu ${ }^{1}$, Q. Zhang ${ }^{2}$, Chang Sheng Fan ${ }^{1}$ \\ ${ }^{1}$ Department of Business Management, Shaanxi Radio \& TV University, Xi an, Shaanxi Province, 710119, China \\ ${ }^{2}$ School of Management, Xi`an Jiaotong University, Xi`an, Shaanxi Province, 710049, China \\ preliu@eyou.com, qzhang@stu.xjtu.edu.cn
}

\begin{abstract}
This paper aims to identify application impacts with the emerging government micro-blog of various social functions. Some countries claimed that the developing of micro-blog was driven mainly by the innovative demand in the society especially of the youths online net-users. However, this claim requires further validation of empirical testing approach to make clear what are actual factors? To achieve this goal, it is required to conduct analyzing factors with broader social background scope and administrative perspective. Based on a quantitative analyses approach, this study analyzes user's preference causes toward micro-blog, and the most dominant factors influencing users. This paper discusses the development of Government micro-blog in China, and a case study to evaluate social usability and media impacts of China's government institutions. Conclusions are drawn that micro-blog will bring a completely revolution to break incentive incompatibility in the procedure of democratic supervision and administrative leaders ought to address to the modern social information function.

Index Terms - Government micro-blogging, Impact, usability, Factor Analysis
\end{abstract}

\section{Introduction}

Over the past three years, the micro-blog has become an important role in advocating campaign of micro-blog. Recent reports on the development of micro-blog reveal different patterns of implementation (Ebbers and Van Dijk 2007; Rose 2005; West 2005), including a serious digital divide that exists around the world. A monitoring report offered by Data Center of China Internet (DCCI) shows that active accounts registered in micro-blog has surpassed 65 million at the end of 2010, and will exceed 150 million in 2011, 280 million in 2012 and 460 million in 2013. Micro-blog is exactly a virtual social network based on the real relationships with near peers, friends, and relatives in the first place providing an inherent and contagious advantage(Roger, 1995). At present, the public in China is mostly entertaining in the micro-blog online. How to deliver nutritional information and attract the followers' active focusing attention is the first step to undertake the significant responsibilities and improve the professional image of leadership for the government. Micro-blog provides users with the shortest path to exchange messages more frequently and effectively, especially when searching for valuable information related to the government.

In government institutions, it is an important orientation for administration to apply the emerging online information channels to strengthen inner human resource purity and maximize administrative quality. Particularly, under the leadership of Government Reconstructing Initiative of China centre authority, more and more local government in China have entered into citizen-oriented work reform and devoted great efforts to improve administrative performance with internet paths. The micro-blog is the use of timely information and technologies for better public communication services for citizens and society. Governments tend to evacuate and launch micro-blog exchange based on understanding of what citizens need without actually measuring what increases citizens' willingness to adopt micro-blog. At present, the trajectory of micro-blog growth in China is still obscure. This paper aims to identify application impacts with the information quality and interface usability for assessing functions of micro-blog from a specific perspective and the standpoint of the Chinese government. Based on a quantitative analyses approach, this study analyzes user's preference toward micro-blog, and analysis of factors influencing users of micro-blog.

\section{Methodology}

The general research framework of this study adopted a problem-based research cycle presented by Levy, et al (2008), as become now a standard form for academic research. In Levy's research cycle, a research endeavor might best be viewed as a normative structure that incorporates a number of distinct but related elements, including the research problem or key issue that drives the whole research, along with the goals or targets, literature review, methodology, results, and conclusions. We here also absorb the style to run our expedition. The research problem aims to unclose the application effects of micro-blogging on common citizens in developing China, and evaluation tools are used to make it specific. The study framework centre on assessment effects around the feasibility, which essentially detail what actually micro-blog plays over the social aspects, thus answering the question: "What will the government do to actively make use of micro-blog advantageous benefits?" This study employs both qualitative and quantitative data analyses to produce and explore new findings.

This paper presents an evaluation path based on the concept of a public value methodology for micro-blog portal evaluation. This concept is a new approach for performing an analysis and evaluation of governance quality. The key points of this concept were developed in the mid-90, and achieved its academic popularity in the later days. This concept takes its root in public administration practice, as a basis for monitoring the efficiency of administrative reforms and the development of public service quality standards. Generally, 
such purposes are perhaps most clearly identifiable and applicable in respect of universal entitlements such as health, education, housing and sanitation, personal security, emergence management, national safe security and social justice. Moore also argues that public values must relate to citizens' desires and perceptions, thus it mainly tackles the actual problem in the people from within.

One of the modern applications of this concept mentioned above is the analysis and evaluation of various services and tools of governance quality improvement. Nowadays, one of the most effective tools of government quality improvement is the development of e-government, especially related technical platforms such as the micro-blog. In reality, the author has adapted and extended this concept to address micro-blog, with application to the case study. We quoted him as saying "the Public Value can be defined as the value created by government activities", and the added value arising from these activities can be interpreted as the difference between the benefits received from and resources given to the government by society. In mapping the territory of what it is the public value, Kelly et al(2002).identify three categories; (1) public services, (2) public policy outcomes, and (3) public trust. By these three elements, the public value concept is closely interrelated with the good governance principles firstly developed by the United Nations, and also with the governance quality criteria used by the World Bank to calculate GRICS (Governance Research Indicator Country Snapshot) indices (2007). Enlightenments cast from the discussion lies that public value concept enabled an analysis and systemization of the characteristics used by different researchers to evaluate the level of development and quality of micro-blog portals, which eventually resulted in the vital specification of five major indicators for assessing regional government portals: (1) Openness (2) Transparency (3) Interactivity (4) Citizen-centricity and (5) Usability. The Author has adopted and extended this concept to evaluate micro-blog in Indonesia. In this paper, we try to draw some enlightenment from the concept, and make evaluations towards micro-blog on the context of China.

\section{Data Collection}

We mainly applied the network channels to receive the key data. Specifically, data collection via online was undertaken through SNS aboard of China Sina, Tencent, and Netease micro-blogging in China, as well as government institution websites of provincial levels. Also around $30 \%$ questionnaire sheets were distributed in some public institutions like schools, train stations, fast food sectors, libraries, art museums etc. The time sequence of online data collection took place between the beginning of June 2012 and the end of Feb. 2013. After the data collection, the questionnaires were orderly numbered for data entry into SPSS (Statistical Package for Social Sciences, 19.0 Edition), so that entry errors could be maximum corrected. All questions were tested using a frequency table approach for incorrect ranges and unusual responses, and the source questionnaires were double checked for accuracy of data entry that is guarantee for further analysis.

The following data analysis will be used in this study. Comparative analysis of two groups of samples will be applied to show the data tabulation and sample characteristics. A matrix chart will be showed to visualize the characteristics between of current micro-blog services rating and the user expectations. T-tests will be adopted to test hypotheses of equality of two means (means of current services rating and the user perceived expectations).

\section{A. Descriptive Statistic}

For convenience, here we just take Sina as the typical channel for micro-blog for impact diffusion. Sina micro-blog surprisingly covers a great deal of public celebrities from the Chinese mainland, Hong Kong and Taiwan, even Hollywood. By June 2013, 200 million users have registered in Sina Weibo. While it took Twitter almost 3 years to achieve this. Almost 45 million micro-blogs are sent everyday. Sina Weibo smooth the mechanism of users' content production and strengthen the integration of enormous information expansion.

Table 1 shows the descriptive statistic of score of each statement to evaluate the impact the Micro-blogging services. Such statistic values as $N$, Sum, Mean, and Std. Dev in the tables indicate a number of valid respondents, number of the "yes" answer, average, and standard deviation, respectively.

TABLE.1 Rating of the Effects of Surveyed Data

\begin{tabular}{|c|c|c|c|c|}
\hline Code & $\mathbf{N}$ & Sum & Mean & Std. Dev \\
\hline $\mathrm{X} 1$ & .224 & 182 & .76 & .438 \\
\hline $\mathrm{X} 2$ & .226 & 189 & .82 & .359 \\
\hline $\mathrm{X} 3$ & .223 & 232 & .92 & .229 \\
\hline $\mathrm{X} 4$ & .218 & 215 & .82 & .436 \\
\hline $\mathrm{X} 5$ & .232 & 189 & .70 & .492 \\
\hline $\mathrm{X} 6$ & .242 & 176 & .69 & .436 \\
\hline $\mathrm{X} 7$ & .251 & 175 & .68 & .483 \\
\hline $\mathrm{X} 8$ & .239 & 149 & .82 & .462 \\
\hline $\mathrm{X} 9$ & .238 & 148 & .79 & .389 \\
\hline $\mathrm{X} 10$ & .228 & 155 & .73 & .369 \\
\hline $\mathrm{X} 11$ & .239 & 158 & .49 & .512 \\
\hline $\mathrm{X} 12$ & .228 & 169 & .64 & .448 \\
\hline $\mathrm{X} 13$ & .228 & 109 & .59 & .482 \\
\hline $\mathrm{X} 14$ & .225 & 192 & .58 & .289 \\
\hline $\mathrm{X} 15$ & .241 & 158 & .82 & .227 \\
\hline $\mathrm{Y}$ & .231 & 213 & .69 & .387 \\
\hline Valid N & 179 & & & \\
\hline
\end{tabular}

\section{B. Factor Analysis}

As a vital factor-reduction tool, Factor Analysis (FA) is adopted to show significance variables and detect structure in the relationships between variables and users preferences to micro-blog services. The factor analysis attempts to identify underlying variables, or factors, that explain the pattern of correlations within a set of observed variables. 


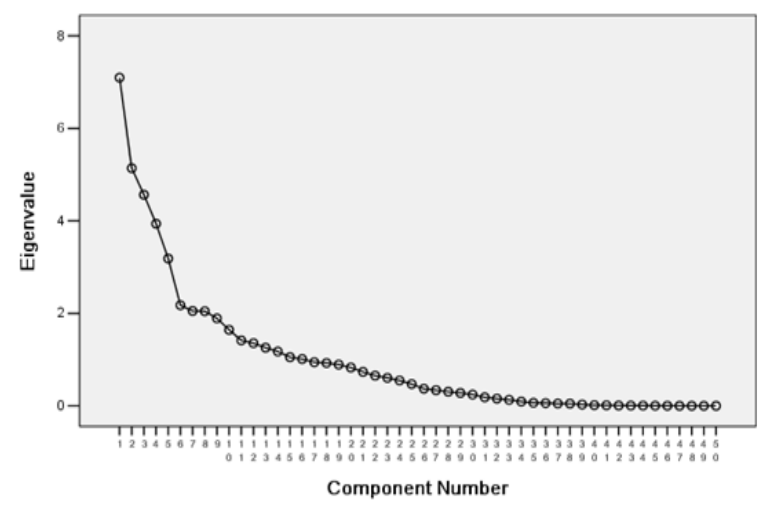

Fig. 1 Scree Plot for Evaluated Variables

According to routine statistical principles, factor analysis ought to conform to certain standard for guaranteeing validity. Figure 1 shows a result of statistical testing of the evaluated variables in the scree plot drawn from the selected data storage, indicating feasibility of factor analysis in our study. Table 1 shows a result of a principal component analysis. The first column indicates the factors component. The second column is total of Eigen values which indicate the variance on the new factors that were successively extracted. In the third column, these values are expressed as a percent of the total variance. By counting, factor 1 accounts for 52.734 percent of the variance, factor 2 is for 13.276 percent, factor 3 is for 8.194 percent and so on. The fourth column contains the cumulative variance extracted. As we can see four at least main factors could be extracted from the factor analysis. Table 3 reveals full component transformation matrix.

TABLE. 2. Result of Components Analysis

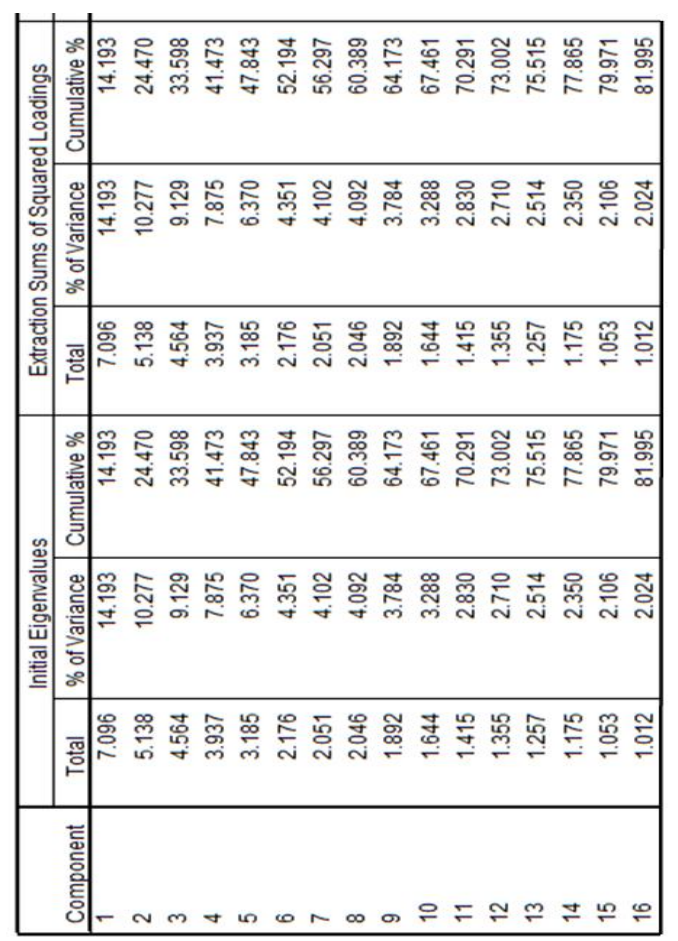

TABLE 3. Results of Components Transformation Matrix

\begin{tabular}{|c|c|}
\hline$\circ$ & 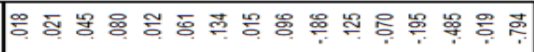 \\
\hline 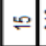 & 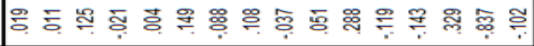 \\
\hline \pm & 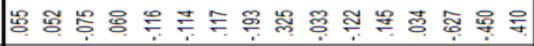 \\
\hline$=$ & 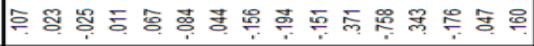 \\
\hline$\simeq$ & 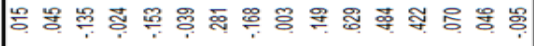 \\
\hline$=$ & 珰毛 \\
\hline$=$ & 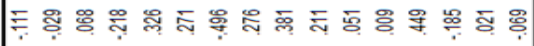 \\
\hline$\Phi$ & 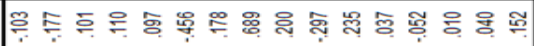 \\
\hline$\infty$ & 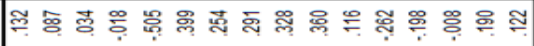 \\
\hline-1 & 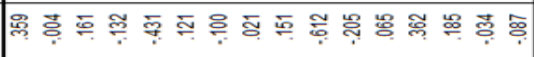 \\
\hline$\infty$ & 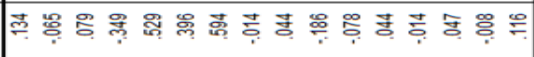 \\
\hline$\infty$ & 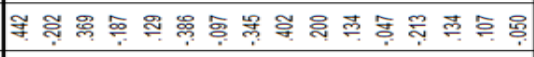 \\
\hline+ & 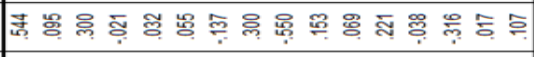 \\
\hline$m$ & 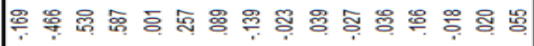 \\
\hline$\sim$ & 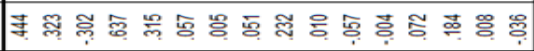 \\
\hline- & 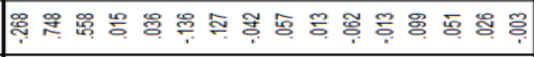 \\
\hline 产 & \\
\hline
\end{tabular}

As the matrix reveals there could be five more component extracted in the process, and Baetlett's testing result also indicates that the significance level is equivalence to nearly 0 and variables' reducing is not needed in this study. The rule is we drop the variable unless a factor extracts at least as much as the equivalent of one original.

\section{FINDINGS}

The number of netizens (wangmin) in China has ranked No.1 in the world. Micro-blogging is an important channel for public opinions, which can effectively promote community inclusion. With the prevalence of micro-blog and the decline of traditional media, it's not easy to judge whether micro-blog has a positive or negative effect on Chinese citizens, as also one of the main targets for this study. The result shows that near $79 \%$ of the respondents feel that the micro-blog could make benefits for common citizens. Over $91 \%$ respondents believe that they need the micro-blog services to make easy to have access to government's information and improve their specialized knowledge perspective. $79 \%$ of respondents reflected that the micro-blog services will challenge the current web administration ecology and are urgently needed to strengthen transparency of governance institutions, especially on the aspect of important information publication. However, only $54 \%$ of the respondent agreed that micro-blog can reduce government's bureaucracy and $72 \%$ respondents feel that the micro-blog services can improve the participation of citizen to democracy processes.

The impact of improving quality of government public services was agreed by $69 \%$ of the respondents. Around $50 \%$ of the respondents feel that the micro-blog services can influence the economy activities such as tourism and 
investment. Only $43 \%$ of the respondents agreed that the services improving job vacancy for the citizen. The most dominant factor that influences users to choose micro-blog services is factor 1 (we named as "effectiveness"). this was affecting $51.2 \%$ of users. The factor 1 has high correlation with variable $\mathrm{X} 8$ (reducing cost to get government services), X7 (reducing government's bureaucracy), X9 (shorter time to get public services), X10 (improving quality of government public services) and X5 (improving a sense of safety and security of citizen). The factor 2 effect $16.2 \%$ of the microblog users and is correlated to the variable X13 (improving the economic activities), X12 (improving number of investment), and X14 (improving job vacancy for the citizen). We named the factor 2 as "economically prospects". The factor 3 effect $7.7 \%$ of the users and is correlated to the impact variable $\mathrm{X} 4$ (make citizen easy to access government's information), X2(improving transparency of governance), X1 (improving participation of citizen to democracy), and X3(improving knowledge perspective of citizen). We named the factor 3 as "openness and transparency". The result indicated that around $64 \%$ of the users felt that the micro-blog services offer a positive impact to the users on the government effectiveness, economic prospects and openness \&transparency.

\section{Conclusions}

The survey result indicated that the micro-blog services gave benefit for citizen and most of them felt that they can gain a positive impact from the micro-blog services. The positive impacts represent high citizen expectation to the online digital services in bringing government institutions more effective, open and transparent to improve effectiveness of affair processes together with a good public administrative accountability. Generally speaking, web administration represents one aspect of public administration. We need to take a cautious and rigorous attitude towards micro-blogging service, trying to avoid the conflicts between government and the netizens. To do this, the government have to conduct frequently update of their services in content and technology. The content update is needed for the citizen to provide newest information and services. The technology update is also needed to make service access more convenient and applicable. Form is only the carrier of the content, not its purpose. A healthy environment will make micro-blogs play a positive role of public exchange and social correction. To improve the usability, accessibility, and effectiveness of micro-blog services for citizens, it is necessary to conduct the services' impacts evaluation periodically. The research gathered information representing important feedback and opinions from the users. The micro-blog website developers will then need to reflect such feedback in the redesign and reengineering of micro-blog services.

Irreversibly, micro-blogging service has been the mostfavored medium, just as the twitter in the world. Government should take full consideration of its positive side. Although it is troublesome right now to handle the overwhelming discontent and false information, we must make possible endeavors. Definitely what we must and should do is to build a coordinating society. Only in this way can we reach a compromise between government and the public opinion. To make much clearer the current status of micro-blog development in China and its impacts for the citizen, we consider that it is necessary to conduct other studies with different parameters. It is required to conduct analyzing some factors with broader socio-economic framework such as social status and demographics parameters. It is also necessary to study micro-blog of province and district level of local government in China.

\section{Acknowledgment}

We would like to express our great appreciation to assistant Professor Y. Jiang, Doc. G. Ma, Xi`an University of Post \& Communications, for their unselfish guidance throughout this research. Also, we would like to thank our students from Shaanxi Business College for their proofing support as well as data gathering contributions during the writing of the paper.

\section{References}

[1] Ebbers, W. E. and G. M Van Dijk. "Resistance and Support to Electronic Government, Building a Model of Innovation”. Government Information Quarterly, vol. 24, no.3, pp.554-575. 2007.

[2] Rose. "A Global Diffusion Model of E-Governance". Journal of Public Policy vol.25, no.1. pp.5-27. 2005.

[3] West, Darrell M. Digital Government: Technology and Public Sector Performance. Princeton, NJ: Princeton University Press. 2005.

[4] E.M. Rogers. Diffusion of Innovation. New York: Free Press, 1995.

[5] Levy, Timothy J. Ellis and Yair. Framework of Problem-Based Research: A Guide for Novice. 2008.

[6] Q. He. "Researchers on the Development of a Research-Worthy Problem. Informing Science" International Journal of an Emerging Transdiscipline: vol 8, pp. 17-33. 2001.

[7] Moore, M. (1995). "Creating Public Value Strategic Management in Government." Harvard University Press.

[8] D. Gruhl, R. Guha, D. Liben-Nowell, and A. Tomkins. "Information diffusion through blogspace". In Proc. of the 13th international conference on World Wide Web, pp.491-501, 2004.

[9] Kelly, G., G. Mulgan, and S. Muesrs. "Creating Public Value: An analytical framework for public service reform. London." Strategy Unit discussion paper, Cabinet Office. London. 2002

[10] M. Cha, A. Mislove, and K.P. Gummadi. "A measurement-driven analysis of information propagation in the flickr social network". Proceedings of the 18th international conference on World wide web, pp.721-730, 2009.

[11] J.C. Bertot, P.T. Jaeger, S. Munson, and T. Glaisyer. "Social Media Technology and Government Transparency". Computer, vol. 43, no. 11, pp. 53-59, 2010. Nov.

[12] C. Maciel, L. Roque, and A.C. Bicharra. Interaction and communication resources in collaborative e-democratic environments: The democratic citizenship community. Information Polity - Government 2.0: Making Connections between citizens, data and government, vol. 15, no $1 \& 2$,pp. 73-88, 2010, April.

[13] F. D. Wigand. Twitter in Government: Building Relationships One Tweet at a Time. 2010 Seventh International Conference on Information Technology, pp.563-567, 2010.

[14] Golubeva, A.A. "Evaluation of regional government portal on the basis of public value concept: Case study from Russian Federation." International Conference on Electronic Governance, pp. 394-397. Macao: ACMpress.2007. 